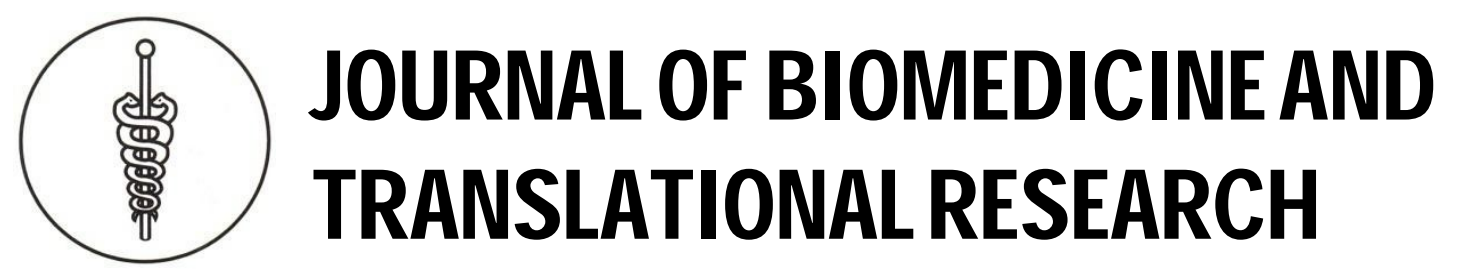

Copyright $@ 2016$ by Faculty of Medicine Diponegoro University and Indonesian Doctor Association, Central Java Region

Short Communication

\title{
Genetic Analysis for the Diagnosis of Disorders of Sexual Development in Indonesia
}

\author{
Sultana MH Faradz \\ Center for Biomedical Research, Faculty of Medicine, Diponegoro University, Semarang
}

\section{Article info}

History :

Received 15 August 2016

Accepted 24 November 2016

Available 29 December 2016

\begin{abstract}
Disorders of sex development (DSD) is defined by congenital conditions in which development of chromosomal, gonadal, or anatomical sex is atypical, while in clinical practice this term means any abnormality of the external genitalia. DSD patients have been managed by a multidisciplinary gender team in our center as collaboration between Dr. Kariadi province referral hospital and Faculty of Medicine Diponegoro University. Diagnosis should be established by specific physical examination hormonal, chromosomal and DNA studies; and imaging for most of the cases depending on indication.

Since 2004 the involvement of molecular and cytogenetic analysis so far can diagnosed many of the DSD cases. Most of the genetically proven cases were Congenital Adrenal Hyperplasia, Androgen Insensitivity syndrome and sex chromosomal DSD that lead abnormal gonadal development. Many of them remain undiagnosed, further testing such as advanced DNA study should be carried out in collaboration with other center in overseas. The novel genes were found in some cases that contributed for the management of DSD. Information for medical professionals, patients, family members and community about the availability and necessity of DSD diagnosis should be delivered to improve DSD management and patient quality of life.
\end{abstract}

\section{INTRODUCTION}

Disorder of Sex Development (DSD) formerly termedintersex, hermaphrodite, or ambiguous genitalia. This group of conditions now is being called disorders of sex development (DSDs) according to "Consensus statement on management of intersex disorders" ${ }^{1}$. DSD is divided into three primary roots based on karyotype namely $46, \mathrm{XX}$; 46,XY and Sex Chromosome DSD. Secondary root is depicted based on hormone assessment and imaging and the tertiary root is obtained based on molecular and/or histopathology examination. Classification of sex chromosome DSD include the following:45,X (Turner syndrome and variants); 47,XXY ( Klinefelter syndrome and variants) and 45, $\mathrm{X} / 46, \mathrm{XY}$ (mixed gonadal dysgenesis, ovotesticular DSD); 46,XX/46,XY (chimeric, ovotesticular DSD). Classifications of 46,XY DSD include the following:disorders of testicular development (complete and partial gonadal dysgenesis); disorders of androgen synthesis (complete and partial androgen insensitivity; disorders of anti mullerian hormone/ AMH, androgen biosynthesis defect) and other (severe hypospadias, cloacalexstrophy). Classifications of 46,XX DSD include the following:disorders of ovarian development (ovotesticular DSD, testicular DSD, gonadal dysgenesis) and Androgen excess (fetal Congenital Adrenal Hyperplasia/ $\mathrm{CAH}$ ) and other ( vaginal atresia, cloacalexstrophy).

Previous Terminology and $\begin{array}{r}\text { Revised } \\ \text { Nomenclature of Disorders of } \\ \text { Development }\end{array}$ Sexual




\begin{tabular}{lc}
\hline \multicolumn{1}{c}{ Previous } & Revised \\
\hline \multicolumn{1}{c}{ Intersex } & $\begin{array}{c}\text { Disorders of Sex } \\
\text { Development (DSD) }\end{array}$ \\
Male pseudohermaphrodite & 46, XY DSD \\
Undervirilization of XY Male & 46, XY DSD \\
Undermasculinization of XY & 46, XY DSD \\
Male & 46, XXDSD \\
Femalepseudohermaphrodite & 46, XXDSD \\
Overvirilization of XX female & 46, XXDSD \\
Masculinization of XX female & Ovotesticular DSD \\
True hermaphrodite & 46, XX testicular DSD \\
XX male or XX sex reversal & $46, X Y$ complete gonadal \\
XY sex reversal & dysgenesis \\
\hline
\end{tabular}

The ability to diagnose these conditions has advanced rapidly in recent years. In most cases clinicians in developed countries can promptly make an accurate diagnosis and counsel parents on therapeutic options. However early gender assignment and reconstruction surgery has been challenged because of the dilemma of gender identity development in later life. Molecular analysis as part of health care service in Indonesia is limited in research center of the universities setting; therefore a complete diagnosis with genetic analysis quite often cannot be done. Proper diagnosis and integrated treatment is important for DSD patient, in order to avoid medical, psychological and social aspect in adult life.

Hughes identified quite a lot of gene mutation in $46, X Y D^{D S D}{ }^{2}$. Significant number of gene mutation in 46, XY with the clinical presentation of undervirilisation or gonadal dysgenesis were found by our group such as DAX-1 duplication, SF1 mutation and other more common mutation such AR gene and Cyp 21 mutation ${ }^{3,4,5}$. Studies from a number of different countries and cultural differences showed that while many patients managed sequentially, gender counseling as well as sexual counseling should be part of the multidisciplinary service available to patients with DSD to avoid gender dysphoria ${ }^{6 .}$ Genetic counseling is not very common as part of health care in Indonesia, however it should be also given to patient and family as many DSD is actually caused by inherited genetic diseases ${ }^{7}$. Urological problems and prevention to the development of malignancy in both males and females with DSD deserve more attention ${ }^{8}$. The Ministry of Health of the Indonesian government should pay more attention to the management of DSD cases; provide diagnostic facilities and treatments such as hormonal and glucocorticoid medication. The challenges for the future will include the further investigation of the gene mutation influenced to sex development that relevant with clinical implications. International collaboration with multidisciplinary expertise should be encouraged.

\section{Services and Genetic analysis in our center}

The gender team called as Sexual adjustment (PenyesuaianKelamin) team in our center is the only multidisciplinary team in Indonesia that manages patients with DSD. This collaborative team between Dr Kariadi province referral hospital and Faculty of Medicine Diponegoro University is consisted of experts in urology surgery, plastic surgery, gynecology, anesthesiology, Adult and Child endocrinology, genetics, andrology, psychiatry, psychology, pathology, legal , religion and social-medical staff. The process of establishing the correct diagnosis starts with serial hormonal and genetic testing then referring the patients and family to the multidisciplinary team for further analysis of possible treatments.

Patients were referred to Center for Biomedical Research, Faculty of Medicine Diponegoro University, Semarang, Indonesia for chromosomal and gene analysis. Before drawing the blood all patients were physically examined for specific DSD. Diagnosis were firstly established using chromosome and common hormonal analysis such as testosterone, $\mathrm{LH}, \mathrm{FSH}$, and $17 \mathrm{OH}$ progesterone.

Genetic analysis has been done for chromosome analysis, rarely FISH analysis, some gene analysis such as SRY gene, AZF gene, AR gene and Cyp21 gene. Chromosomal aberrations were the most common found of DSD cases in the first line of diagnosis. Other advanced and scarce gene mutations have been done in collaboration with other center in overseas on the basis of joint research. Most of the cases were 46, XY DSD followed by 46, XX DSD andSex Chromosomal DSD respectively. The genetically proven $46, X Y$ DSD cases were Androgen Insensivity Syndrome ( AR gene mutation) and the majority cases of 46, XX DSD were Congenital Adrenal Hyperplasia.

Many stages and genes are involved that lead to gonadal formation and differentiation, thus it is not always possible to identify the causes of the disorders. Consequently, the scope of molecular genetic analysis has markedly expanded. Although clinical and psychological management have already been done, many undiagnosed DSD should 
be later analyzed using advanced molecular techniques. Recommendations on what is needed in the diagnosis and management of DSD should be promoted among medical community including the obstetrician. Many primary care doctors unaware to such laboratory testing and it is unavailable in all regency hospitals (type B hospitals) in Indonesia. These genetic testing is not affordable and not covered by the government health insurance (BPJS) because it is not known and not a priority by the government stake holder who manages the government public insurance.

\section{REFERENCES}

1. Hughes I A, Houk C, Ahmed S F, Lee P A and LWPES/ESPE (2006). Consensus Group disorders Consensus statement on management of intersex. Arch. Dis. Child,91;554-563

2. Hughes IA, Nihoul-Fékété C, Thomas B, CohenKettenisPT(2007). Consequences of the ESPE/LWPES guidelines for diagnosis and treatment of disorders of sex development. Best Pract Res ClinEndocrinolMetab, 21(3):351-65.

3. Juniarto AZ, van der Zwan YG, Santosa A, Hersmus R, de Jong FH, Olmer R, et al. (2012) Application of the new classification on patients with a disorder of sex development in indonesia. International journal of endocrinology. 2012:237084.

4. Juniarto, A.Z., van der Zwan, Y.G., Santosa, A., Ariani, M.D., Eggers, S., Hersmus, R., Themmen, A.P., Bruggenwirth, H.T., Wolffenbuttel, K.P., Sinclair, A., White, S.J., Looijenga, L.H., de Jong, F.H., Faradz, S.M., Drop, S.L. (2016) Hormonal evaluation in relation to phenotype and genotype in 286 patients with a disorder of sex development from Indonesia. Clinical Endocrinology, 1-11

5. Eggers S, Smith KR, Bahlo M, Looijenga LHJ, Drop SLS, Harley VR, Koopman P, Faradz SMH, Sinclair AH (2014). Whole exome sequencing combined with linkage analysis identifies a novel deletion in NR5A1 in a family with 46,XY disorders of sex development and 46,XX premature ovarian insufficiency. Eur J Hum Genet. 23(4):486-93.

6. Warne GL, Raza J. (2008). Disorders of sex development (DSDs), their presentation and management in different cultures. Rev Endocr Metab Disord. Sep;9(3):227-36.

7. Zayts O, Sarangi S, Thong MK, Chung BH, Lo IF, Kan AS, Lee JM, Padilla CD, Cutiongco-de la Paz EM, Faradz SM, Wasant P (2013). Genetic counseling/consultation in South-East Asia: a report from the workshop at the 10th Asia pacific conference on human genetics. J Genet Couns. Dec;22(6):917-24

8. Pleskacova J, Hersmus R, Oosterhuis JW, Setyawati BA, Faradz SM, Cools M, Wolffenbuttel KP, Lebl J, Drop SL, Looijenga LH (2010). Tumor risk in disorders of sex development. Sex Dev. Sep,4(45):259-69 